\title{
AS IDEOLOGIAS LINGUÍSTICAS SUBJACENTES AO ENSINO DA PRODUÇÃO ESCRITA EM UM LIVRO DIDÁTICO DE LÍNGUA PORTUGUESA ${ }^{1}$
}

\author{
Célia GAUDEDA² \\ Universidade Estadual de Ponta Grossa
}

\begin{abstract}
RESUMO: Neste artigo, tem-se por objetivo discorrer sobre as ideologias linguísticas subjacentes ao ensino da produção escrita em um livro didático de língua portuguesa utilizado em uma escola da Rede Municipal de Ensino de Curitiba - PR. Inicialmente, são tecidas algumas discussões sobre esse termo, ideologias linguísticas, que tem se sobressaído no campo dos estudos da linguagem; posteriormente, explana-se sobre Política Linguística, com foco no Plano Nacional do Livro Didático (PNLD); por último, toma-se um Livro Didático de Português (LDP) e se faz a análise de uma de suas propostas de ensino da produção de textos escritos, objetivando constatar que ideologias linguísticas são disseminadas. A sustentação teórica deste artigo está, principalmente, em Moita Lopes (2013); Kroskrity (2004); Woolard e Schieffelin (1994); Rivas (2014), Bunzen (2005; 2011) e Tormena (2007). Após a análise empreendida, concluiu-se que os sujeitos autores do LDP são orientados por ideologias linguísticas que não desvinculam os falantes das dinâmicas sociais. Além disso, foi possível verificar que eles primam por uma variedade da língua, a norma urbana de prestígio, embora reconheçam a existência de outras variedades. Assim, acabam por colaborar com a manutenção de uma língua no Brasil, atendendo aos interesses do PNLD, uma das Políticas Línguísticas no país.
\end{abstract}

PALAVRAS-CHAVE: ideologias linguísticas; livro didático; ensino da produção escrita.

ABSTRACT: This paper aims to discuss the linguistic ideologies underlying the teaching of written production in a didactic book of Portuguese language used in a school of the municipal school network of Curitiba (PR). The initial discussion is about the term, linguistic ideologies, which has been highlighted in the field of language studies; after that, it is explained Language Policy, focusing in the National Plan for Didactic Book (PNLD, for the acronym in Portuguese); lastly, a Didactic Book of Portuguese (LDP, in Portuguese) is taken to be analyzed in one of its propositions for teaching written texts production, in order to verify the linguistic ideologies that are disseminated in them. This paper theoretical support is, mainly, in Moita Lopes (2013); Kroskrity (2004); Woolard and Schieffelin (1994); Rivas (2014), Bunzen (2005; 2011) and Tormena (2007). After the analysis, the conclusion is that the subjects who are the authors of the LDP are oriented by linguistic ideologies that do not unlink speakers from social dynamics. Moreover, it was possible to observe that they give primacy for one variety of the language, the prestige urban standard, although they recognize the existence of other varieties. Thereby, they end up collaborating to the maintenance of a

\footnotetext{
${ }^{1}$ Trabalho realizado para a conclusão da disciplina Pesquisa em Linguagem ministrada pela Professora Doutora Cloris Porto Torquato, no Programa de Pós-Graduação em Linguagem Identidade e Subjetividade, da Universidade Estadual de Ponta Grossa.

${ }^{2}$ Graduada em Letras. Especialista em Língua Portuguesa e Literatura brasileira. Professora da Rede Municipal de Ensino de Curitiba. Mestranda do Programa de Pós-graduação em Linguagem, Identidade e Subjetividade, da Universidade Estadual de Ponta Grossa ( $1^{\circ}$ ano).
} 
language in Brazil, meeting the interests of PNLD, one of the Language Policies of the country.

KEYWORDS: linguistic ideologies; didactic book; written production teaching.

\section{Introdução}

Tendo em vista a afirmação de Moita Lopes (2013), a de que é fundamental que sejam realizadas reflexões "sobre as ideologias linguísticas que orientam falantes, escritores etc. em suas práticas linguísticas cotidianas, estudiosos da linguagem, professores de línguas em formação e em serviço e planejadores de políticas públicas" (MOITA LOPES, 2013, p. 51), se elabora o presente estudo reflexivo partindo do livro didático de língua portuguesa, intitulado Português uma língua brasileira (MENNA; FIGUEIREDO; VIEIRA, 2012), utilizado em turmas de $6^{\circ}$ ano de uma escola da Rede Municipal de Ensino de Curitiba - PR. Portanto, temse aqui como intuito central verificar que ideologias linguísticas têm orientado e são veiculadas pelos sujeitos autores desse instrumento, que é capaz de exercer influências na vida de docentes e discentes, especialmente no que diz respeito à produção de textos escritos.

Inicialmente, são tecidas algumas considerações sobre as ideologias linguísticas, que, segundo Kroskrity (2004), são as crenças construídas sobre as línguas como são usadas em seus mundos sociais. Esses novos termos, esses novos estudos teóricos envolvendo a linguagem são necessários porque o quadro sociopolítico do século XXI não é mais o mesmo e, sendo assim, "não é mais possível continuar a usar um referencial teórico e suas ferramentas analíticas que explicavam a linguagem, o português e seus usos, típicos da modernidade colonial em um mundo pós-colonial" (MOITA LOPES, 2013, p. 30), que sofre os impactos da globalização em todos os seus campos sociais.

Na sequência, à luz de Tormena (2007), parte-se para uma breve explanação sobre Política Linguística, que inclui o Plano Nacional do Livro Didático (PNLD, doravante). Também, destacam-se as ideias de Bunzen (2005), que afirma que desde a década de 60 o Livro Didático do Português (LDP, de ora em diante) vem sendo investigado sob várias correntes teóricas; ao contrário de alguns outros que o defendem como um suporte, esse autor o defende como um gênero discursivo, que dissemina os conhecimentos predominantes de cada época, relacionados às modalidades da aprendizagem e ao tipo de saberes e de comportamentos que se deseja promover. Portanto, é um instrumento que propaga a ideologia modalizante do ensino da língua, de acordo com o período.

Feito isso, segue-se adiante tomando como objeto de análise um LDP, em uso em escola da Rede Municipal de Ensino de Curitiba - PR. Dentre todas as propostas de ensino da escrita nele apresentadas, uma delas foi selecionada - a proposta de produção do gênero entrevista - para serem identificadas as ideologias linguísticas disseminadas pelos sujeitos autores, especialmente em relação à produção de textos escritos. Para tanto, é feito um resgate da sustentação teórica do estudo, que foi encontrada em Moita Lopes (2013); Kroskrity (2004); Woolard e Schieffelin (1994); Rivas (2014), Bunzen (2005; 2011) e Tormena (2007).

\section{Ideologias linguísticas}

O contexto atual é caracterizado por inúmeras transformações nos seus diversos campos (cultural, político, econômico, dentre outros). Em meio a esse cenário, no qual tudo e todos se movimentam cada vez mais, é necessária, também, uma movimentação que conduza 
a um repensar sobre que tem sido chamado de português (MOITA LOPES, 2013). Isso inclui a utilização de novos construtos teóricos e teorizações que não desconsiderem esses fenômenos que têm eclodido socialmente.

Para o autor supracitado, ao contrário do que houve em outros campos das ciências sociais, que não desprezaram o surgimento e as discussões relativas ao fenômeno da globalização, os linguistas custaram a perceber a relevância dessas teorias. Essa demora se explica pelo fato desses estudiosos terem se prendido às teorizações típicas do século XX, que ignoravam as "avassaladoras teorizações sobre globalização, pós-modernidade, pósestruturalismo, pós-colonialismo, feminismos, sexualidade, antirracismo, etc." (MOITA LOPES, 2013, p. 19). Ou seja, as pesquisas no campo dos estudos da linguagem foram sendo feitas a partir do que seus idealizadores adquiriram à época de sua formação, sem dar abertura às novas ocorrências, aos novos fenômenos sociais instaurados.

Não obstante, esse quadro está se alterando e novas teorias para tratar de questões inerentes ao fenômeno da linguagem, no contexto atual, estão vindo à tona. Conforme registrado por Moita Lopes (2013), pesquisadores como Woolard e Schieffelin, (1994); Kroskristy (2006); Pennycook (2001, 2007); Bauman e Briggs (2003); Moita Lopes (2006; 2011); Blommaert (2010); Blommaert e Rampton (2011), são alguns dos que têm se ocupado dessas novas teorizações.

Quanto ao construto teórico despontado nesse novo cenário, trata-se de ideologias linguísticas. García (2010) colabora ao afirmar que esse termo se "originó dentro de la antropologia lingüística norteamericana en los años '70, con un obvio antecesor en la tan visitada y siempre revisada ideología, noción cara a distintos campos dentro de las ciências humanas y sociales" (GARCÍA, 2010, p.2). Trata-se, portanto, de um termo originário do campo da antropologia linguística, ligado ao discutidíssimo termo ideologia, que vem conquistando seu espaço nas discussões contemporâneas envolvendo a linguagem.

Quanto ao que seriam essas ideologias, destaca-se a afirmação de um dos estudiosos que tem tratado da questão, Kroskrity (2004). De acordo com suas palavras, "em resumo, ideologias linguísticas são as crenças ou sentimentos sobre as línguas como são usadas em seus mundos sociais." (KROSKRITY, 2004, p. 498, tradução nossa) ${ }^{3}$. Cabe apontar que essas crenças construídas pelos usuários acerca da linguagem seguramente não são naturais; elas são influenciadas pelas forças culturais do meio em que eles encontram-se inseridos.

Nessa perspectiva, Woolard e Schieffelin (1994) destacam que.

Ideologias linguísticas são significativas para a análise social assim como linguística porque elas não tratam apenas de linguagem. Ao contrário, tais ideologias preveem e encenam ligações da linguagem com identidade de grupo e pessoal, com estética, com moralidade, e com epistemologia. Através de tais ligações, elas frequentemente sustentam instituições sociais fundamentais. (WOOLARD; SCHIEFFELIN, 1994, p. 55-56, tradução nossa) ${ }^{4}$

\footnotetext{
3 In sum, language ideologies are beliefs, or feelings, about languages as used in their social worlds. (KROSKRITY, 2004, p. 498).

${ }^{4}$ Ideologies of language are significant for social as well as linguistic analysis because they are not only about language. Rather, such ideologies envision and enact links of language to group and personal identity, to
} 
O que as autoras evidenciam no excerto é que a discussão que envolve ideologias linguísticas não se resume à discussão sobre língua, e nisso reside a sua valiosa importância. Uma vez que se trate de ideologias linguísticas, trata-se, também, de sujeito(s) e suas identidades, do meio em que eles vivem, da relação entre língua, cultura e nação, do poder exercido pela língua numa sociedade e em suas instituições, ou seja, ao abordá-las, há que se considerar um conjunto de fatores.

Cabe enfatizar que são possuidores de ideologias linguísticas tanto aqueles que pesquisam, que estudam a língua, quanto aqueles que apenas fazem uso dela, como, por exemplo, os falantes e os escritores. Ao tratar sobre essa questão, Kroskrity (2004) afirma que

\begin{abstract}
As ideologias linguísticas não são meramente aquelas ideias que partem da "cultura oficial" da classe dominante, mas muito mais presentes como um conjunto de crenças diversas, independentemente de serem implícitas ou explícitas, usadas pelos falantes de todos os tipos como modelos para a construção de avaliações linguísticas e para o engajamento em atividades comunicativas. (KROSKRITY, 2004, p. 497, tradução nossa) ${ }^{5}$.
\end{abstract}

Portanto, as ideologias linguísticas não são exclusivas de um grupo. Elas são múltiplas e se manifestam, não importando o contexto em que o sujeito está inserido. Um usuário comum, não necessariamente um docente da área da língua ou um pesquisador, por exemplo, manifesta sua ideologia linguística em situações tais como modificar sua linguagem em função do contexto em que se encontra; evitar se pronunciar diante de pessoas de contextos diferentes do seu por vergonha, medo de alguma espécie de julgamento etc.

Kroskrity (2004), ainda, apresenta outros exemplos de ideologias linguísticas: crenças que existem acerca da superioridade ou inferioridade de idiomas específicos, crenças sobre como determinadas línguas são adquiridas, crença sobre a importância de se aprender uma língua ancestral, mesmo que ela não seja a usada em casa, mantida em certas culturas.

Esse mesmo autor, ao abordar a noção de ideologia linguística, postula que se trata de algo que abrange algumas dimensões, convergentes entre si. Essas dimensões, apresentadas para auxiliar na caracterização do que seriam as ideologias linguísticas, são cinco: (1) interesses de grupos ou individuais; (2) multiplicidade de ideologias; (3) consciência de falantes; (4) funções mediadoras das ideologias; e (5) papel da ideologia da linguística na construção da identidade (KROSKRITY, 2004).

Para o estudioso, esses cinco níveis são "camadas de significação parcialmente sobrepostas mas analiticamente distinguíveis" (KROSKRITY, 2004, p. 501, tradução nossa) ${ }^{6}$. Isso significa, conforme elucidação feita por Cáceres (2014), que, de alguma maneira, os

aesthetics, to morality, and to epistemology $(41,104,186)$. Through such linkages, they often underpin fundamental social institutions. (WOOLARD; SCHIEFFELIN, 1994, p. 55-56).

${ }^{5}$ Certainly language ideologies are not merely those ideas which stem from the "official culture" of the ruling class but rather a more ubiquitous set of diverse beliefs, however implicit or explicit they may be, used by speakers of all types as models for constructing linguistic evaluations and engaging in communicative activity. (KROSKRITY, 2004, p. 497).

${ }^{6}[. .$.$] overlapping but analytically distinguishable layers of significance[...] (KROSKRITY, 2004, p.501).$ 
vários conceitos para o termo convergem a um ponto central, que perpassa qualquer um dos níveis: "entender a ideologia linguística como as crenças sobre a língua, sejam elas demonstradas explicitamente ou compartilhadas implicitamente" (CÁCERES, 2014, p.107). Portanto, qualquer que seja o nível, aponta para uma constituição de crenças e sentimentos sobre as línguas tal como são usadas no mundo.

No presente estudo, a abordagem será feita em um livro didático, mais especificamente, numa das propostas de produção escrita que são idealizadas por seus autores a fim de ser ensinada aos sujeitos do $6^{\circ}$ ano do Ensino Fundamental. Será adotado, então, o termo ideologia linguística como a expressão, explícita ou implícita, das concepções de um grupo sobre a língua portuguesa ou, a ideologia linguística de um grupo responsável por um objeto cultural construído sócio-historicamente e legitimado culturalmente, que acaba por influenciar no ensino da língua portuguesa e, consequentemente, na vida dos sujeitos. Porém, antes da análise, abaixo a opção foi por adentrar em algumas discussões que dizem respeito à política linguística e ao livro didático de português, um objeto cultural complexo, como uma manifestação dessa política.

\section{Plano Nacional do Livro Didático: uma Política Linguística Implícita}

Já há muito tempo ocorre a publicação de diretrizes e de documentos que explanam acerca de como deve ser norteado o ensino do português nas instituições escolares brasileiras. Bunzen (2011), ao elaborar uma reflexão sobre o surgimento e a ascensão da disciplina escolar Português, aborda alguns aspectos que reconfiguram essa disciplina no século XX e assevera que, nesse período, o destaque tem sido para a construção dos programas oficiais e para a relação entre os estudos acadêmicos sobre o ensino de língua materna e as políticas públicas (PCN, PNLD, PNBE etc.).

Todavia, não é somente para atender ao campo do ensino que a língua tem sido focada. Segundo Tormena (2007), no decorrer da história da humanidade, a língua sempre foi alvo de intervenções. Entretanto, só recentemente essas intervenções se tornaram objeto de reflexão sistemática, dentro daquilo que tem sido nomeado como Política Linguística (PoL, doravante) e Planejamento Linguístico.

Essa autora, ao discorrer sobre a Política Linguística, que "caracteriza-se por ser uma intervenção sobre a sociedade através das línguas" (TORMENA, 2007, p. 11)", sustentada em Klinkenberg (2005), menciona a existência da política linguística explícita e implícita. A primeira teria seu foco na língua, tendo por intuito modificá-la, firmá-la ou ainda bani-la. Para exemplificá-la, ela cita o Diretório dos Índios, de 1757, que veio para determinar, no Brasil, o uso e o ensino do português em detrimento de todas as outras línguas que existiam, principalmente as indígenas. Já na PoL Implícita, a língua integra a política, mas não é o seu objeto central e nem o seu objetivo final. Tal política, "geralmente, objetiva expor e/ou firmar uma língua, intervindo em seu status e não em seu corpus." (TORMENA, 2007, p. 21). Como exemplos dessa política são citados os programas, os parâmetros, as orientações e recomendações etc.

Ainda segundo essa autora, dentre as duas políticas, a que tem predominado no Brasil é a PoL Implícita. O que tem havido são programas educacionais que objetivam orientar a ação docente, propiciar a formação continuada ou ainda se preocupar e cuidar da qualidade do material didático que é utilizado, ou seja, há políticas implícitas. Não se pode desconsiderar o 
fato de que tudo isso carrega consigo uma concepção de língua e de ensino de língua que, conscientemente ou não, são repassados ao público alvo dos programas (TORMENA, 2007).

Dentre essas ações tem destaque o PNLD, que tem por objetivo prover às escolas públicas de ensino fundamental e médios livros didáticos e acervos de obras literárias, obras complementares e dicionários ${ }^{7}$. Neste estudo, conforme já explicitado, os interesses estão voltados para o LDP, mais especificamente um deles, adotado por uma unidade educacional municipal de Curitiba - PR.

Em consonância com Bunzen (2005), os LDP, cujo papel é divulgar e legitimar sobre como deve ser norteado o ensino de português, têm sido objeto de investigação à luz de diferentes correntes teóricas. Em diálogo com os estudos bakhtinianos, esse autor assume o LDP como um modo de interação verbalmente "criado no âmbito de determinada esferas da atividade humana, constituídas sócio-historicamente e que reflete as condições específicas e as finalidades de cada uma das suas esferas de origem e circulação" (BUNZEN, 2005, p. 27). Portanto, a sua compreensão é de que esse é um objeto complexo, construído historicamente em meio a complexa rede de intercalações, marcado por aspectos gráficos-editoriais (cores, imagens, boxes etc.), ou seja, ao olhá-lo detalhadamente, é possível estudá-lo como um gênero do discurso constituído por vários outros gêneros intercalados, assim como é constituído um romance ou outros gêneros midiáticos.

Partindo do pensamento bakhtiniano, esse autor entende que, à medida que os autores de livros didáticos, aliados a outros agentes envolvidos no processo de edição, fazem a seleção de determinados objetos de ensino e elaboram unidades didáticas visando ensinar tais objetos, estão produzindo um enunciado em um gênero do discurso, cuja função seria "re(a)presentar para cada geração de professores e estudantes o que é oficialmente reconhecido, autorizado como forma de conhecimento sobre a língua(gem) e sobre as formas de ensino-aprendizagem" (BUNZEN, 2005, p. 27).

Souza e Aires (2015), que situam o PNLD como uma PoL Implícita e o LDP como um elo de expressão dessa política, também se filiam à concepção do LD como um gênero discursivo. Um dos pontos que corroboram para que elas assumam esse posicionamento, está relacionado com a função dos autores de livros didáticos. No sentido bakhtiniano do termo, são eles os produtores do enunciado, direcionado para uma determinada geração, para um determinado público.

Portanto, o LDP configura-se como um objeto cultural portador de saberes, práticas de ensino, concepções de aprendizagem, tendo como produtores vários agentes (autores, editores, avaliadores, revisores, professores etc.), que situam-se em determinados tempos históricos e que trabalham mais ou menos em favor do mesmo objetivo, um alinhamento de interesses (BUNZEN, 2005), em torno do ensino da língua portuguesa, sustentados pela ideologia de seus produtores.

Ao tratar dos textos produzidos, Barros (2007), ancorada no pensamento do filósofo russo Bakhtin, também corrobora asseverando que o texto é um objeto significante, um produto da criação ideológica, que não existe fora da sociedade; portanto, ligado a tudo o que existe nela (contexto histórico, social, cultural etc.) e os seus produtores, os homens, não só são conhecidos por meio deles, como se constroem enquanto objetos de estudos "nos ou por meio dos textos" (BARROS, 2007, p. 22).

\footnotetext{
${ }^{7}$ Informações disponíveis em: http://portal.mec.gov.br/pnld/apresentacao. Acesso em: 19/01/2016.
} 
Diante do exposto, toma-se o texto LDP como um objeto cultural inserido numa cadeia de elos discursivos, para ser ouvido e compreendido, com o intuito de se descobrir quais são as escolhas ideológicas que carregam e que disseminam, em se tratando do ensino de português.

Feita essa breve incursão sobre o PNLD, a seção subsequente centra-se na análise do LDP elegido.

\section{Livro didático: considerações à luz das ideologias linguísticas}

Para o presente estudo, selecionou-se o LDP intitulado Português uma língua brasileira (MENNA; FIGUEIREDO; VIEIRA, 2012), que atualmente é utilizado por turmas do $6^{\circ}$ ano do Ensino Fundamental, regularmente matriculados em uma unidade escolar da Rede Municipal de Ensino de Curitiba. Nessa unidade educacional, pretende-se realizar a coleta de dados que integrarão o corpus de análise de uma dissertação de mestrado que encontra-se ainda em seu estágio inicial, e que tem como objetivo investigar como tem se dado o ensino da modalidade escrita de linguagem, em turmas de estudantes que frequentam o referido ano de escolarização. A análise da ideologia linguística propagada, em relação ao ensino da escrita, já seria uma pequena entrada em um campo que está prestes a ser explorado com mais afinco.

Antes de focar o objeto selecionado para a análise, a produção escrita de texto, convém fazer uma breve menção à organização feita pelos autores-criadores do LDP selecionado, ou aqueles que, conforme Faraco (2009), dão forma ao conteúdo e não apenas registram, passivamente os eventos, "mas a partir de uma certa posição axiológica" (FARACO, 2009, p. 90) recortam-os e reorganizam-os esteticamente.

O volume 6, o qual foi tomado para estudo, está organizado em quatro unidades e nove capítulos. Em sua apresentação, as autoras explicam que abordaram no livro "os mais diversos assuntos da atualidade: situações familiares e escolares, temas de interesse dos jovens, um pouco do que vemos na TV, no teatro, no cinema nas revistas e nos jornais" (MENNA; FIGUEIREDO; VIEIRA, 2012, p. 3). Aqui se constata a intrínseca ligação dos agentes responsáveis pela produção a seu meio histórico e cultural, sendo por ele influenciados.

De acordo com os pressupostos teóricos adotados anteriormente, o autor assume papel relevante no percurso de produção, pois é o responsável por selecionar, fazer as escolhas tendo em vista o(s) seu (s) interlocutor(es), que são, seguramente, os que vão orientar a composição, o estilo, a forma de enunciar. As autoras estão conectadas a espaços sociais e, ao tratar do que é relevante para ser ensinado em língua, retiram dele o que consideram significativo de ser apreendido, e isso a partir de suas ideologias orientadoras.

Em cada um dos capítulos do LDP, o destaque inicial é para "O que você vai aprender neste capítulo". Logo após localiza-se "Olhe e veja" (imagens para serem lidas). Na sequência, vem a seção "Leitura", na qual se apresenta o gênero principal que será abordado no capítulo e as seções "Estudo de texto" e "Linguagem e recursos expressivos". Posteriormente, se apresentam "Outra(s) leitura(s)", as propostas de "Produção oral", "Produção escrita" e "Para refletir sobre a língua", momento em que são trabalhados conteúdos morfológicos e sintáticos. Constam também as seções "Atividades de ampliação" e "O que você aprendeu". Ao final de cada unidade, há uma proposta de "Projeto" para ser 
desenvolvido em equipe. Nessa seção, há orientações sobre como proceder para realizar exposições das produções textuais elaboradas.

Posta essa organização, caberia retomar a importância de se olhar para o LDP como um objeto histórico-cultural plurilinguístico, um gênero do discurso complexo, elaborado a partir da intercalação de outros gêneros (VIANA; SOUZA, 2013), direcionado para o propósito disseminar uma teoria, uma ideologia linguística sobre como deve se dar o de ensino de língua portuguesa.

Quanto às propostas de produção de textos, foram localizadas dez: produção de narrativa de memórias (individual); de diálogo (em dupla); roteiro turístico (em grupo); entrevista (dupla); narrativas de aventura (individual); história em quadrinhos (grupo); conto popular (individual); mito (dupla); resumo (individual); cartaz (grupo). O primeiro "Projeto de Exposição" é proposto após a produção da narrativa de memórias, do roteiro e das entrevistas. Após serem produzidos os quatro gêneros que vêm na sequência (os que vêm depois da entrevista), a orientação é para que se faça o "Projeto Roda de Leitura" para a comunidade e, por último, para as duas últimas propostas, a sugestão é fazer uma campanha, a "Campanha a gente e o meio ambiente".

Já pelo título da coleção, Português uma língua brasileira, é possível inferir uma manifestação ideológica. Com ele tem-se a ideia de que tanto o investimento quanto a promoção serão em torno de uma língua em específico; é um título imponente, capaz de levar os sujeitos a ver e a entender a língua portuguesa como uma língua de uma nação, o Brasil. Portanto, conforme a seleção linguística feita para a elaboração do título, nota-se valoração ao português, em detrimento de outro idioma que no Brasil também possa ser falado.

É possível pensar aqui naquilo que é chamado de ideologia da língua comum. Nesse caso, há o reconhecimento da diversidade de línguas, mas uma é a "que tem o direito de entrar no mundo do mercado com um valor determinado na relação de produção e consumo de bens intelectuais e de ganhos materiais" (RIVAS, 2014, p.141). No caso, quem ganha esse direito é o português.

É mister mencionar que, ainda na visão de Rivas (2014), o problema de se pensar e de se imaginar uma língua comum que unifica as nações é que não há homogeneidade em termos linguísticos; há sim uma diversidade de povos que compõem as sociedades, e, por conseguinte, há outras formas de pensar o mundo, não podendo ser desconsiderada a língua desses povos, que é que define essa diversidade. Contudo, em se tratando de uma PoL implícita, como é o caso do LDP, conforme já tratado, não poderia ser diferente a abordagem em relação à língua portuguesa, que é a língua oficial do país, senão a que feita com o intuito de ressaltá-la e mantê-la.

Quanto às variedades da língua, as autoras salientam que, ao falar, "não existe um modo mais correto ou adequado que os demais" (MENNA; FIGUEIREDO; VIEIRA, 2012, p. 82). O que deve ser levado em consideração para utilizar um ou outro modo é o contexto comunicativo, mas afirmam que, de todas as variantes que existem, foi selecionada uma, conhecida como "normas urbanas de prestígio" (MENNA et al., 2012, p. 83, grifo das autoras), sendo essa adotada nas escolas, usada pelas pessoas de mais prestígio social, que têm maior poder econômico, e é a mais empregada nos meios de comunicação. Portanto, nesse quesito, suas ideologias primam pela norma urbana de prestígio.

O foco, a partir de agora, será em como é feita a abordagem do ensino da produção de um gênero: a entrevista. Cabe assinalar que todas as propostas estão articuladas ao gênero 
discutido nas seções de leitura e todas vêm com as etapas do processo de produção do texto descritas: planejamento, escrita, revisão, avaliação e produção do texto final.

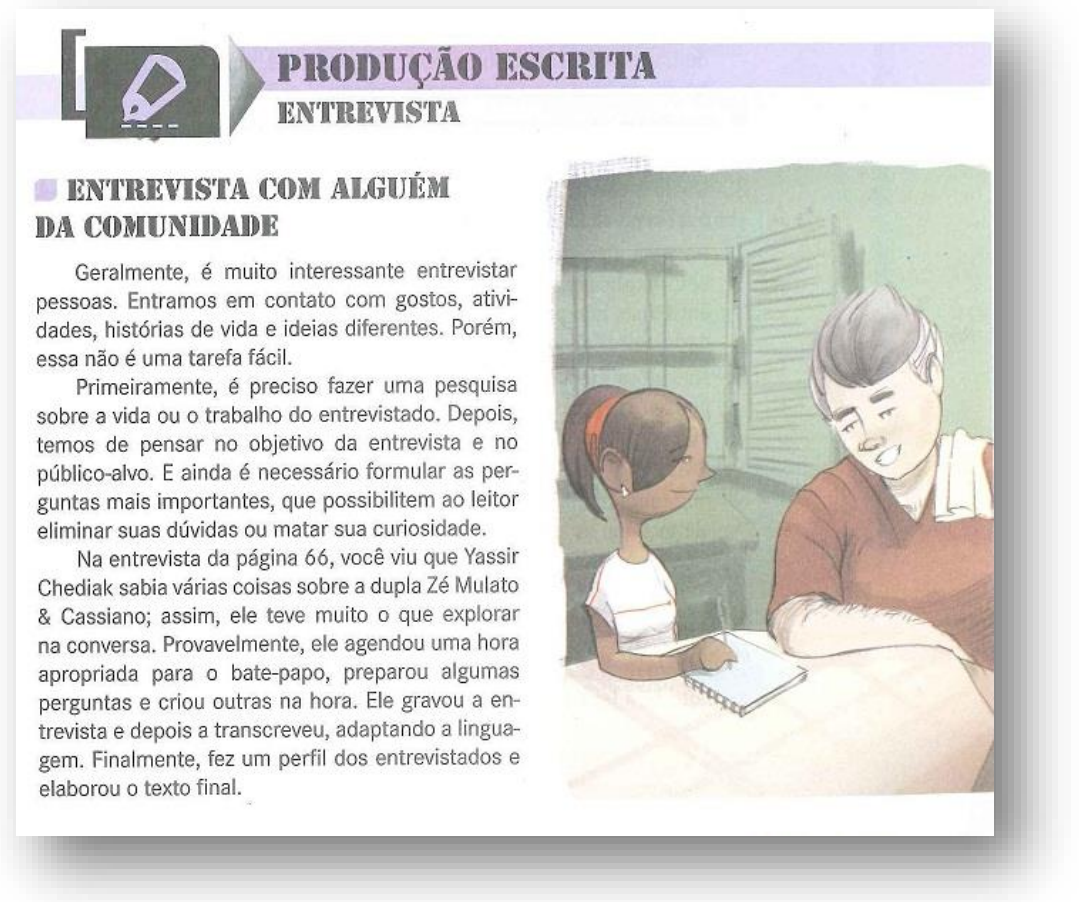

Figura 1: Seção "Produção escrita", livro 1, unidade 1, capítulo 3 Fonte: Menna, Figueiredo e Vieira (2012, p. 85).

Nota-se que não há uma artificialidade da situação proposta. A produção é de um texto autêntico, que circula efetivamente no meio social, a entrevista. Portanto, a produção é de um gênero discursivo, que é uma forma típica de enunciado, elaborado nas situações reais de comunicação, como forma de ação e de interação social. As autoras relembram a existência da entrevista apresentada no capítulo e discorrem sobre alguns passos indispensáveis para que ela possa ser feita. Considera-se essa retomada importante, pois permite ao aluno rememorar as condições necessárias para a produção do gênero, além de atentá-lo para recorrer a ele em busca das suas características típicas, caso sinta necessidade.

Mais interessante ainda seria se, em algum momento, fossem sugeridos o contato e a leitura de outras entrevistas, presentes nos suportes nos quais, de fato, elas circulam socialmente. Assim, os estudantes visualizariam o texto que está vivo no meio social e ainda teriam a possibilidade de internalizar mais elementos caracterizadores do gênero, podendo trazê-los para sua produção. Na sequência da proposta, encontram-se as seguintes orientações: 
Agora vamos ao desafio. Forme dupla com um colega e sigam as dicas

a seguir. As entrevistas da turma comporão o projeto Quem Somos Nós.

1. Vocês vão entrevistar alguém que considerem importante para sua comunidade, escola ou cidade. Não é necessário que seja alguém famoso. Pode ser alguém que tenha algum talento, alguém que saiba contar histórias antigas do lugar onde vocês moram ou uma pessoa que conheça os costumes da sua comunidade.

2. Definido quem será o entrevistado, a dupla vai estudar para preparar a entrevista. É necessário pesquisar sobre o entrevistado para poder elaborar as perguntas.

3. Se possivel, providenciem um gravador ou usem o celular para fazer a gravaçäo e tirem uma foto do entrevistado.

Figura 2: Seção "Produção escrita", livro 1, unidade 1, capítulo 3 Fonte: Menna, Figueiredo e Vieira (2012, p. 86).

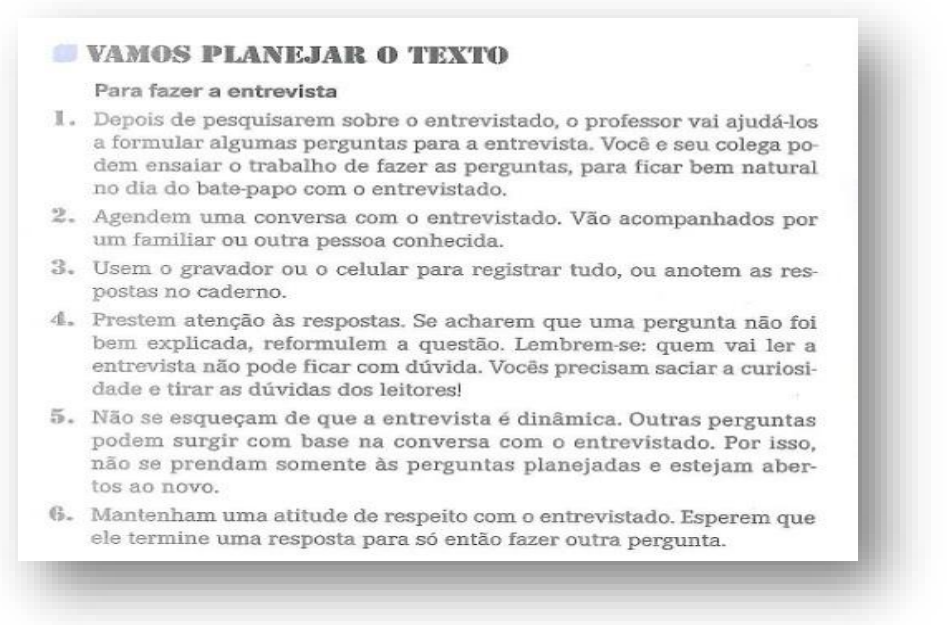

Figura 3: Seção "Produção escrita", livro 1, unidade 1, capítulo 3 Fonte: Menna, Figueiredo e Vieira (2012, p. 86).

Das dez propostas trazidas, essa está dentre as seis para serem realizadas em duplas ou em grupos, aspecto interessante de ser destacado, considerando que é no ato interativo entre os pares que acontecem as trocas, o diálogo, a construção conjunta do aprendizado. As autoras deixam evidente o que será feito com a produção após sua realização (onde o texto irá circular); o interlocutor não será somente o professor, mas um público maior.

Outro ponto relevante da proposta é o que diz respeito à atuação do docente durante o processo, que não deverá ficar à margem dele; ao contrário, deverá desempenhar o seu importante papel de mediador. Cabe mencionar que, embora haja a preocupação com a veiculação do gênero, o suporte para a circulação não se aproxima tanto do real, já que entrevistas costumam ser veiculadas em sites, em jornais, em revistas e dificilmente em murais, como se propõe no Projeto final. Outro ponto para ser pensado é o que diz respeito à pesquisa sobre a vida do entrevistado como condição prévia para elaboração da entrevista. Se ele não é famoso, talvez seja difícil fazer um levantamento de informações sobre sua vida 
antes da entrevista; os estudantes não teriam de onde pegá-las e, nesse caso, caberia ao docente pensar em outros meios para obtenção dessas informações.

Na sequência da proposta, encontram-se orientações para elaborar o perfil, que deverá ser instigante e conter informações, tais como local de nascimento, profissão e outros dados que forem interessantes. Feito isso, os próximos passos são estes:

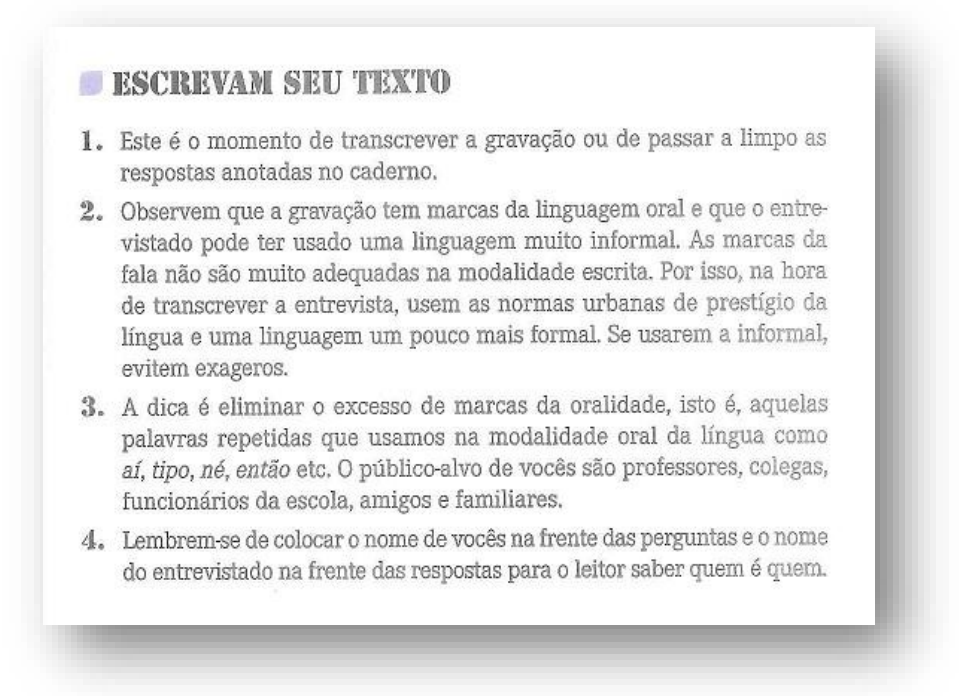

Figura 4: Seção "Produção escrita", livro 1, unidade 1, capítulo 3 Fonte: Menna, Figueiredo e Vieira (2012, p. 87).

As orientações demonstradas na figura acima referem-se ao momento em que a dupla irá fazer a transcrição da gravação a fim de dar forma ao gênero entrevista, por escrito. No decorrer do capítulo, as autoras abordam as diferenças existentes entre as modalidades oral e escrita da linguagem, e salientam que "não escrevemos como falamos e não falamos como escrevemos" (MENNA; FIGUEIREDO; VIEIRA, 2012, p. 74). Pontuam, ainda, que, "apesar de sermos brasileiros e falarmos a mesma língua, não falamos todos do mesmo modo" (MENNA; FIGUEIREDO; VIEIRA, 2012, p. 81). As autoras trazem textos explicativos sobre as diferenças no emprego do vocabulário, sobre as diferenças na pronúncia e variação social, mas sustentam a posição de que a "escrita segue regras, que regulamentam o modo como devemos escrever, relacionadas à necessidade de se manter a unidade do idioma nacional" (MENNA; FIGUEIREDO; VIEIRA, 2012, p. 83). Afirmam, também, que essas regras denominadas normas urbanas de prestígio são estudadas nas aulas de Língua Portuguesa a fim de que todos os sujeitos tenham a possibilidade de de acessá-las e aprendê-las para empregá-las quando o contexto exigir. No fragmento em destaque, as autoras reforçam a necessidade de fazer a adequação e utilizar as normas urbanas de prestígio no ato da produção escrita do gênero entrevista.

Nesse ponto da discussão, retoma-se o construto ideologias linguísticas, resgatando Moita Lopes (2013). O autor pontua que as teorizações e os projetos discursivos que são elaborados em torno da linguagem são norteados pelas ideologias que seus mentores possuem. Constata-se, mediante o exposto até aqui, que, em termos de ensino de um gênero em sua da modalidade escrita de linguagem, a entrevista, as autoras revelam ideologias 
linguísticas que não desvinculam os falantes das dinâmicas sociais. Orienta-se a produção de um gênero que circula socialmente, estabelece-se um público-alvo e uma finalidade para a escrita.

Constata-se que elas têm em mente e disseminam o trabalho com gênero discursivo, ou com a produção de linguagem (enunciados), no caso aqui na modalidade escrita, que se realiza em condições e com finalidades específicas nas diferentes situações de interação social, apresentando certas formas típicas (estrutura composicional e estilo), que as caracterizam, possibilitando assim que sejam identificadas e nomeadas pelos participantes da situação de interação (BAKHTIN, 1997).

No que diz respeito às autoras defenderem a norma urbana de prestígio, constatam-se ideologias linguísticas que primam pela preservação de uma forma de se expressar em detrimento de outras existentes, embora essas sejam por elas reconhecidas, conforme já descrito. Woolard e Schieffelin (1994), ao tratarem das ideologias linguísticas como concepções culturais sobre línguas, linguagem e comunicação, alegam que

tais ideologias preveem e encenam ligações da linguagem com identidade de grupo e pessoal, com estética, com moralidade, e com epistemologia. Através de tais ligações, elas frequentemente sustentam instituições sociais fundamentais". (WOOLARD; SCHIEFFELIN, 1994, p. 55-56, tradução nossa $)^{8}$.

Reitera-se aqui a forte influência de outros discursos, dentre eles o discurso do PNLD, na formação das ideologias que são reveladas, disseminadas pelas autoras ao elaborarem o material para a manutenção de uma língua, em uma de suas variedades.

Conforme destaca Rivas (2014), “as ideologias fundadas na coletividade são reassimiladas de forma individual como visão parcial da realidade mesmo se estas foram concebidas nas relações de poder de um ou de vários grupos hegemônicos" (RIVAS, 2014, p. 135). Com isso, se sustenta a hegemonia de uma língua em um território, no nosso caso, no Brasil.

Cabe ainda destacar aqui uma das dimensões das ideologias linguísticas apresentadas por Kroskrity (2004) e debatida por Moita Lopes (2013), a quinta dimensão, que explica que o fenômeno da ideologia linguística está relacionado ao modo como as ideologias são utilizadas na construção das identidades, tanto culturais, quanto nacionais, tais como nacionalidade e etnia. Trata-se de uma dimensão importante, já que os conceitos de nação, de etnia, são dependentes dela. Daí vem a necessidade de os governos investirem na educação e na manutenção de uma língua em específico.

Cabe pontuar, então, que o LDP, objeto cultural complexo, produzido mediante uma soma de vozes, não somente cumpre o papel no que se diz respeito ao ensino de língua portuguesa, mas também funciona como um instrumento político do Estado atuando em prol da manutenção dessa língua no País.

\footnotetext{
${ }^{8}[\ldots]$ such ideologies envision and enact links of language to group and personal identity, to aesthetics, to morality, and to epistemology $(41,104,186)$. Through such linkages, they often underpin fundamental social institutions. (WOOLARD; SCHIEFFELIN, 1994, p. 55-56).
} 


\section{Considerações finais}

Nesse estudo, inicialmente foram tecidas considerações sobre as ideologias linguísticas, à luz de Moita Lopes (2013), Woolard; Schieffelin (1994), Kroskrity (2004). A incursão por esse lastro teórico permitiu o entendimento que ideologias linguísticas são crenças e concepções sobre a linguagem, que certamente não são naturais, mas construídas e se manifestam implicitamente ou explicitamente nas práticas comunicativas, podendo servir, em alguns casos, a interesses políticos e econômicos do Estado.

É importante destacar, conforme pontuam Woolard e Schieffelin (1994), que, ao tratarmos de ideologias linguísticas, não tratamos somente de uma língua em si, mas também do(s) sujeito(s) e suas identidades, do meio em que se inserem, da relação entre língua, cultura e nação, do poder exercido pela língua numa sociedade e em suas instituições.

Em seguida, com sustentação em Tormena (2007), houve uma breve discussão sobre o LDP, que é considerado a manifestação de uma PoL Implícita. Na mesma seção, com respaldo em Bunzen (2005) e Souza e Aires (2015), o LDP foi compreendido como um gênero discursivo. Considerou-se, junto a esses estudiosos, que, à medida que as autoras e os demais sujeitos envolvidos no processo de elaboração do material selecionam e organizam a abordagem de determinados objetos de ensino, estão a elaborar um enunciado que se molda em dado gênero discursivo, com a função de disseminar aos docentes e aos estudantes de determinada época, o que é oficial, legitimado em termos de conhecimento e formas de ensino e aprendizado da língua portuguesa, ou seja, estão propagando suas ideologias linguísticas.

Para a análise, na última seção, fora selecionado um LDP que está em uso em turmas de $6^{\circ}$ ano de uma unidade educacional do município de Curitiba - PR, intitulado Português, uma língua brasileira (MENNA; FIGUEIREDO; VIEIRA, 2012). O foco da análise foi em um dos objetos de ensino, a escrita, e a opção foi por uma das dez propostas de ensino da escrita, no caso, do gênero entrevista.

Foi constado que, em termos de ensino de um gênero em sua modalidade escrita de linguagem, as autoras revelam ideologias linguísticas que não desvinculam os falantes das dinâmicas sociais. Isso porque orientam, em etapas, a produção de um gênero que circula socialmente, lembram da necessidade de se pensar no público-alvo, na finalidade para a escrita e na circulação do gênero, embora a forma pensada para a circulação não se aproxime tanto das circunstâncias reais de circulação.

Também foi constado que, embora reconheçam a existência de variantes da língua portuguesa, as autoras defendem que uma delas deve prevalecer, a que é conhecida como norma urbana de prestígio. Pontuam que essa é a adotada nas escolas, a usada pelos prestigiados socialmente, além de ser a mais empregada nos meios de comunicação. Com isso, evidencia-se a ideologia linguística da norma e da delimitação linguística a uma comunidade. Ou como propõe Kroskrity (2004), uma ideologia linguística que representa a concepção de grupos, que seriam aqui os envolvidos na produção do livro, que por sua vez, atendem às orientações do governo, do Estado, cumprindo assim a função do LDP, que trata do ensino e, consequentemente, colabora para a manutenção de uma língua, a língua portuguesa em uma de suas variedades. 


\section{Referências}

BAKHTIN, M. Estética da Criação verbal. Martins Fontes, 1997.

BARROS, D. L. P. de. Contribuições às teorias do texto e do discurso. In: FARACO, C. A.; TEZZA, C.; CASTRO, G. Diálogos com Bakhtin. 4. ed. Curitiba: Editora UFPR, 2007, p.2138.

BUNZEN, C. A fabricação da disciplina escolar Português. Rev. Diálogo Educ., Curitiba, v. 11, n. 34, p. 885-911, set./dez. 2011. Disponível em: file:///C:/Users/PC/Downloads/dialogo5670\%20(2).pdf. Acesso em: 14/01/2016.

Livro didático de Língua Portuguesa: um gênero do discurso. 2005.168 f. Dissertação (Mestrado em Linguística Aplicada). Instituto de Estudos da linguagem da Universidade Estadual de Campinas, Campinas, 2005.

CÁCERES, G. H. Políticas linguísticas em uma escola pública de ensino médio e tecnológico: a oferta de línguas estrangeiras. Trab. Ling. Aplic., Campinas, n(53.1): 103-129, jan./jun. 2014. Disponível em: http://www.scielo.br/scielo.php?pid=S010318132014000100006\&script=sci_arttext. Acesso em : 12/01/2016.

FARACO, C. A. As ideias linguísticas do Círculo de Bakhtin. São Paulo: Parábola Editorial, 2009.

GARCÍA, V. De las ideologías lingüísticas a lo ideológico en los discursos sobre las lenguas. I Jornadas de Diversidad Linguiística y Diálogo Intercultural. Universidad de Buenos Aires, Buenos AIres, 2010.

KROSKRITY, P. V. Language Ideologies. In: DURANTI, A.(ed.). A companion to linguistic anthropology . Blackwell Publishing, 2004, p. 496-517.

MENNA, L.; FIGUEIREDO, R.; VIEIRA, Maria das Graças. Português uma língua brasileira. 1.ed. São Paulo: Editora Leya Brasil, 2012.

MOITA LOPES, L. P. da (Org.). O português no século XXI: Cenário geopolítico e sociolinguístico. São Paulo: Parábola, 2013, p.18-52.

RIVAS, C. C. M. Ideologias linguísticas e políticas de línguas indígenas no Brasil e no México. Anais do V SAPPIL - Estudos de Linguagem, UFF, no 1, 2014. [133] Disponível em:file:///C:/Users/PC/Downloads/147-256-1-PB\%20(2).pdf. Acesso em: 1/01/2015.

SOUZA, E. M. de F.; AYRES, D. J. Livro didático de português: encadeamentos dialógicos para uma política linguística implícita. Domínios de Lingu@gem | Uberlândia | vol. 9/4 | out./dez. 2015.2 Disponível em http://www.seer.ufu.br/index.php/dominiosdelinguagem/article/view/30867/17739. Acesso em: 04/10/2016.

TORMENA, T. A. Política Linguística Implícita na virada do século XXI - O Programa Nacional do Livro Didático. 2007, 177 f. Dissertação (Mestrado em Linguística) Universidade de Brasília, Brasília, 2007. 
VIANA, D. D. C., SOUZA, E. M. de F. Currículo como gênero do discurso: convergências para o livro didático de língua portuguesa. Anais eletrônico do IX Colóquio Nacional e II Internacional do Museu Pedagógico. Vitória da Conquista. Bahia: Edições UESB. 2011. Disponível

em: http://www.repositorios.ufpe.br/revistas/index.php/EUTOMIA/article/view/418/363. Acesso em: 21/01/2015.

WOOLARD, K. A.; SCHIEFFELIN, B. Language ideology. Annual Reviews of Anthropology, v. 23, 1994, p. 55-82. 
